\title{
Dizer a mesma coisa em outras palavras? Questionando o senso comum sobre mediação/tradução durante a formação de docentes de LE: três textos-chave
}

\author{
[Saying the Same Thing in Other Words? Questioning Common Sense about \\ Mediation/Translation during Teacher Training for FL: Three Key Texts] \\ http://dx.doi.org/10.11606/1982-8837254612
}

Ruth Bohunovsky ${ }^{1}$

\begin{abstract}
In the last decades, translation/linguistic mediation has gained prominence and relevance in the area of Foreign Language Teaching (FL). Even so, many works on this subject are still based on a common-sense understanding of translation/mediation that is incompatible with current approaches in the area of Translation Studies. In order to contribute to the training of competent FL teachers in the use and evaluation of linguistic mediation activities in classroom, this article presents three key texts of the field of Translation Studies and suggests their reading and study during the training process of FL teachers.
\end{abstract}

Keywords: Mediation; Translation; FL teacher training.

Resumo: Nas últimas décadas, a tradução/mediação linguística tem ganhado destaque e relevância na área de ensino-aprendizagem de línguas estrangeiras (LEs). Mesmo assim, muitos trabalhos acerca desse assunto ainda partem de uma compreensão da atividade tradutória/de mediação que está enraizada no senso comum e é incompatível com abordagens atuais dos Estudos da Tradução. Com o intuito de contribuir para a formação de docentes de LE competentes no que diz respeito ao uso e à avaliação de atividades de mediação linguística em sala de aula, este artigo apresenta três textos-chave da área dos Estudos da Tradução e sugere sua leitura e seu estudo durante esse processo formativo.

Palavras-chave: Mediação; Tradução; Formação de professores de LE.

\section{Introdução}

Desde o advento do Quadro Europeu Comum de Referência para as Línguas (QECR) (CONSElHo DA EuROPA, 2001), a tradução deixou, oficialmente, de ser um tabu no contexto de

\footnotetext{
${ }^{1}$ Universidade Federal do Paraná, Departamento de Polonês, Alemão e Letras Clássicas, Rua XV de Novembro, 1299, Curitiba, Paraná, 80060, Brasil. E-mail: ruth.bohunovsky@ gmail.com. ORCID: 0000$0003-4412-2678$
}

\section{(cc) BY-NC}


BOHUNOVSKY, R. - Questionando o senso comum sobre mediação/tradução

ensino-aprendizagem de línguas. Para evitar a impressão de que pudesse se tratar de algum tipo de retomada do ultrapassado método de gramática e tradução (Grammatik-ÜbersetzungsMethode) e, também, para marcar a diferença entre o ensino de uma língua estrangeira (LE) ou de uma segunda língua (SL) ${ }^{2}$ e a formação profissional de tradutores e intérpretes, optou-se pela denominação "mediação (linguística)" [Sprachmittlung]. Geralmente, esse termo é usado não em referência à tradução de palavras ou frases cuja finalidade seja explicar um significado ou um fenômeno gramatical em sala de aula, mas sim para remeter à habilidade de usuários de uma língua de assumirem o papel de mediadores entre duas ou mais pessoas falantes de línguas diferentes. Trata-se de uma atividade tradutória bastante comum em nosso mundo globalizado e de intensos movimentos migratórios, marcado cada vez mais pelo convívio de muitas línguas e situações comunicativas em que nem todos os participantes têm uma língua em comum portanto, é uma atividade não profissional e que possibilita a "comunicação entre pessoas que, por qualquer motivo, não conseguem se comunicar diretamente", conforme a definição que consta em Profile Deutsch: Gemeinsamer Europäischer Referenzrahmen (GLABONIAT et al. 2002: 18$)^{4}$.

Após a introdução do conceito de mediação no QECR de 2001, na versão atualizada de 2018 (denominada Companion Volume), a relevância dessa habilidade ganhou ainda mais destaque (RÖSSLER, SCHÄDLICH 2019). Como assinala Elisabeth Kolb (2016) em sua obra de referência intitulada Sprachmittlung: Studien zur Modellierung einer komplexen Kompetenz, em diversos estados da Alemanha e em Portugal a competência em mediação linguística já é prevista e exigida pelo currículo oficial do ensino médio (KolB 2016: 73; cf. também REIMANN 2016: 7-8), mas também na Grécia, na França e na Hungria existem provas oficiais que preveem a avaliação dessa competência (KOLB 2016: 73-77). Todavia, o mesmo não vale para todos os países europeus, pois em muitos deles a mediação linguística ainda não foi integrada às exigências curriculares. No âmbito do ensino-aprendizagem de alemão como língua estrangeira (ALE) ou de alemão como segunda língua (ASL), há diversas publicações relevantes sobre o assunto aqui em foco: desde o caderno 23 da revista Fremdsprache Deutsch (ÜBERSETZEN IM DEUTSCHUNTERRICHT 2000), dedicado integralmente

\footnotetext{
${ }^{2}$ Como o presente artigo entende como seu contexto o ensino de alemão como língua estrangeira no Brasil, não abordamos aqui o ensino de SL e as diferenças entre o ensino de LE e SL.

${ }^{3}$ Todas as traduções de citações neste artigo são feitas por sua autora, salvo indicação contrária.

${ }^{4} \mathrm{~A}$ autora deste artigo atua na área de ALE, portanto os exemplos fornecidos e algumas referências bibliográficas se referem especificamente a essa área. Porém, a argumentação geral do artigo e os três textos-chave nele apresentados dizem respeito ao ensino-aprendizagem de qualquer LE.
} 
ao tema "tradução no ensino de alemão" - publicado ainda antes do lançamento do QECR e da implementação do termo "mediação" nesse contexto - até o número 2 de 2019 da revista Fremdsprachen Lehren und Lernen, organizado por Claus Gnutzmann, Lutz Küster e Karen Schramm e cujo tema é "mediação linguística" [Sprachmittlung] - para citar apenas dois exemplos. ${ }^{5}$ Num levantamento bibliográfico exaustivo, Maria Cristina R. G. Evangelista (2019: 2) reuniu aproximadamente mil referências bibliográficas sobre o assunto "tradução e ensino de línguas". O leque de aspectos abordados é amplo: há argumentações contra a presença de outras línguas ou de qualquer tipo de tradução em sala de aula, reflexões sobre as diversas funções que a tradução pode exercer no ensino de uma LE, propostas metodológicas e/ou didáticas e estudos sobre o papel da tradução literária no âmbito do ensino de LE, assim como críticas a modelos didáticos considerados ineficientes, para citar apenas algumas possíveis aproximações ao tema (cf., por exemplo, Bohunovsky 2011; Evangelista 2019; PASEWAlcK, NeidLinger, Loogus 2014). Poucos desses estudos, porém, se dedicam a um diálogo interdisciplinar com os Estudos da Tradução.

Apesar da diferença óbvia e relevante entre a mediação/tradução cotidiana, não profissional (que interessa à área de ensino-aprendizagem de LE), e a tradução como atividade profissional (que interessa predominantemente aos Estudos da Tradução), os dois campos acadêmicos são áreas afins. Basta observarmos que o conceito de “mediação linguística" se desenvolveu a partir da ideia de uma tradução que "edita o conteúdo" ("inhaltsbearbeitende Übersetzung”), proposta pela Escola de Leipzig nos anos de 1970, e da concepção formulada por Karlfried Knapp e Annelie Knapp Potthoff, que definiram a tradução não profissional como uma atividade em que o mediador faz parte da interação comunicativa (ou seja, ele não fica separado fisicamente dos outros participantes da respectiva comunicação como no caso de tradutores/intérpretes que trabalham em cabines isoladas ${ }^{6}$ ) (KNAPP, KNAPP-POTTHOFF apud REIMANN 2016: 19). Certamente, as duas referidas áreas têm objetivos e finalidades diversos, mas, ao discutirse o conceito de tradução/mediação no âmbito de ensino de LE, um diálogo com os

\footnotetext{
${ }^{5}$ Nas duas revistas citadas, destaca-se o papel pioneiro de Frank G. Königs no contexto da (re)introdução da tradução/mediação linguística no ensino de ALE: na publicação de 2000, Königs é autor do prefácio e de um artigo introdutório; na revista de 2019, o caderno inicia com o obituário do estudioso, assinado por Gnutzmann, Küster e Schramm.

${ }^{6}$ Se essa definição corresponde de fato à realidade do trabalho tradutório profissional, isso é questionável, mas não relevante para o presente artigo, que se concentra na mediação como habilidade não profissional.
} 
BOHUNOVSKY, R. - Questionando o senso comum sobre mediação/tradução

Estudos da Tradução, mesmo que breve e pontual, pode ser benéfico, como tentaremos demonstrar neste artigo.

Partimos da seguinte premissa: antes de pensar sobre propostas didáticas e metodológicas, antes de avaliar vantagens e desvantagens de determinadas atividades de mediação linguística na sua forma escrita ou oral em sala de aula e antes de identificarem-se diferenças entre as diversas funções e os papéis que a tradução ou a mediação ocupa no ensino, é necessário que os professores em formação venham a ter uma compreensão básica (porém condizente com abordagens teóricas atuais), "sobre a natureza das línguas e o que significa traduzir”, conforme já ressaltou Evangelista (2019: 4). Sem tal noção, corre-se o risco de cimentar e não questionar uma ideia sobre língua e tradução que é compatível com o senso comum - geralmente aceita cultural e popularmente -, porém incompatível com análises ou reflexões metódicas de especialistas acadêmicos. Tanto tradutores como docentes de LE são usuários profissionais de línguas, e sua compreensão acerca de seu objeto de trabalho deve, no nosso entender, ir além daquela do usuário leigo, que é mais próxima ao senso comum. No que diz respeito à tradução, entendemos como inerentes ao senso comum as ideias de que existe "equivalência entre palavras de línguas diferentes" (EVANGELISTA 2019: 4) e de que traduzir significa nada mais do que dizer a mesma coisa em outra língua - uma crença que, nas palavras de Evangelista (2019: 4), "precisa ser desconstruída", tanto no "processo de formação de tradutores como também entre aprendizes de LE".

O conceito de equivalência é um dos mais discutidos e criticados por representantes da área dos Estudos da Tradução desde os anos de 1960. Obviamente, os debates a esse respeito não podem ser retomados aqui, nem precisam fazer parte do processo formativo de docentes de LE. No entanto, assim como qualquer estudioso de outro campo de conhecimento que se refira à nossa área de estudo e pesquisa (ensino de LE) pode ser alvo de críticas ao não levar em consideração, por exemplo, o fato de o ensino de LE hoje não seguir mais os preceitos do "método de gramática e tradução" e do "método direto", representantes da área de ensino de LE, ao debruçarem-se sobre o papel e a função da tradução/mediação em sala de aula, deveriam ter conhecimento das discussões e dos conceitos básicos da área de Estudos da Tradução. E um conceito central, objeto de inúmeros debates e discussões ao longo das últimas décadas, é justamente o de equivalência entre palavras, frases, línguas e culturas. Cristina Carneiro 
BOHUNOVSKY, R. - Questionando o senso comum sobre mediação/tradução

Rodrigues, pesquisadora de destaque no campo dos Estudos da Tradução em solo brasileiro e autora de uma tese de doutorado sobre o conceito de equivalência ${ }^{7}$, resume o que podemos chamar de visão unânime da área de tradução no que tange a tal conceito e à relação entre texto de partida e texto de chegada, apesar das divergências entre as muitas vertentes teóricas desse campo de estudo. Conforme Rodrigues,

o texto traduzido é "outro" texto, que mantém outro tipo de relações entre os elementos, exatamente porque as coerções impostas pelas línguas levam a diferentes possibilidades de contextualizações, de remissões, de encadeamentos, de atribuição de valores entre os elementos (RODRIGUES 2000: 95).

Ou, para citar Markus J. Weininger, outro teórico de tradução atuante no contexto acadêmico brasileiro, a equivalência, em "qualquer tipo de tradução" é "ao mesmo tempo inexorável e inalcançável” (WEININGER 2012: 194).

Mesmo os representantes mais conservadores dos Estudos da Tradução concordam hoje que qualquer tradução só pode ser quase a mesma coisa - em alusão aqui ao título dado por Umberto Eco para seu livro sobre suas "experiências de tradução" (ECO 2011) - que seu texto fonte. Ao mesmo tempo, muitos trabalhos publicados na nossa área que se debruçam sobre o uso da tradução/mediação linguística em sala de aula de LE ainda sugerem que o texto traduzido seja a mesma coisa que o "original”. Vejamos alguns exemplos. Em Profile Deutsch... (GLABONIAT et al. 2002), obra de referência para o ensino de ALE e a aplicação das exigências do QECR na prática de ensino, as atividades de mediação linguística são definidas como uma "transmissão" ("Weitergabe”) do “conteúdo" (“Inhalt”) de um texto oral ou escrito (GlABONIAT et al. 2002: 19). No QECR, por seu turno, encontra-se esta observação:

Nas actividades de mediação, o utilizador da língua não está preparado para expressar os seus próprios pensamentos, mas sim para servir de intermediário entre interlocutores que não são capazes de se compreenderem uns aos outros diretamente. (CONSELHO DA EUROPA 2001: 129)

Num curso de formação de professores organizado pelo Estado alemão de BadenWürttemberg, a ministrante definiu entre as "exigências" para a mediação no âmbito do

\footnotetext{
${ }^{7}$ Cf. Rodrigues, Cristina Carneiro. Tradução e diferença: uma proposta de desconstrução da noção de equivalência em Catford, Nida, Lefevere e Toury. 1998. 241f. Tese (Doutorado) - Universidade Estadual de Campinas, Instituto de Estudos da Linguagem, Campinas, SP. Disponível em: http://www.repositorio.unicamp.br/handle/REPOSIP/271182.
} 
BOHUNOVSKY, R. - Questionando o senso comum sobre mediação/tradução

ensino de LE a de "reproduzir o sentido" ("Sinn wiedergeben") e "transmitir, não interpretar" ("übermitteln, nicht interpretieren") $)^{8}$.

À primeira vista - ou seja, sob o prisma do senso comum -, talvez essas definições não levantem nenhuma suspeita. Porém, um rápido olhar a qualquer livro sobre história da tradução ou sobre as teorias que fundamentam essa prática desenvolvido nas últimas décadas pode revelar que hoje é inquestionável a premissa de que a "transmissão" ou "reprodução" de algum sentido supostamente equivalente e/ou intrínseco ao texto fonte é impossível não apenas em qualquer ato tradutório, como também em qualquer ato comunicativo. Iniciar uma reflexão sobre as consequências dessa perspectiva na área de ensino de LE é o nosso objetivo neste artigo.

Cientes de que não é necessário, nem viável, transformar os futuros docentes em especialistas da área de tradução, selecionamos três textos-chave que podem ser úteis para oferecer uma introdução ao assunto e que fornecem uma visão interessante e proveitosa sobre o emprego da tradução/mediação linguística no contexto do ensino de LE. Ao escolhê-los, pensamos especificamente no ensino de LE no Brasil, dando preferência a textos disponíveis em nosso país, em língua portuguesa (embora eles estejam também disponíveis em outras línguas). Além disso, as três publicações versam cada qual sobre um aspecto diferente da tradução, todos relevantes também para discussões no âmbito no ensino de LE.

A seleção do tema deste artigo e dos textos-chave é resultado tanto da atuação da autora como docente nas áreas de ensino de ALE e de Estudos da Tradução, como também de anos de ensino em disciplinas de pós-graduação sobre tradução no ensino de LE em instituições acadêmicas brasileiras e na Universidade de Viena. Foi sobretudo no contexto dessas disciplinas que observamos que os discentes de pós-graduação - embora já formados como professores de ALE, inseridos na prática de ensino e familiarizados com os discursos teóricos nas áreas de didática e linguística -, geralmente não têm conhecimento das reflexões e teorias desenvolvidas nos Estudos da Tradução. Para pensarmos de modo profissional sobre o uso e as funções da mediação linguística no ensino de LE, entendemos que uma aproximação à área de tradução se faz necessária, de modo a estabelecer uma base teórica e crítica que permita aos professores de LE

\footnotetext{
$8 \quad$ Cf. apresentação disponível http://lehrerfortbildung bw.de/u_sprachlit/englisch/gym/bp2004/fb1/mediation/1_impuls/03_sprachmittlung.ppt.
}

Pandaemonium, São Paulo, v. 25, n. 46, mai.-ago. 2022, p. 12-33 
BOHUNOVSKY, R. - Questionando o senso comum sobre mediação/tradução

desenvolverem uma prática de ensino compatível com discursos acadêmicos reconhecidos.

\section{$2 \bigcirc$ significado das palavras: "Aspectos linguísticos da tradução", de Roman Jakobson}

O artigo "Aspectos linguísticos da tradução", de autoria do linguista russo Roman Jakobson, publicado pela primeira vez em 1959 e em inglês, firmou-se como texto-chave dos Estudos da Tradução, mesmo tendo sido alvo de diversas discussões e críticas desde então. ${ }^{9}$ Até hoje, as ideias contidas nesse trabalho continuam sendo adequadas e relevantes para introduzir, de modo sucinto e acessível, o tema da construção do significado lexical. Além disso, o artigo ilustra alguns dos desafios de qualquer tradução, independentemente de seu contexto ou objetivo específico. A tradução brasileira, à qual nos referimos aqui, é de 1976, de autoria de Izidoro Bliksteine e José Paulo Paes.

Jakobson posiciona-se contra o "dogma da impossibilidade da tradução" (JAKOBSON 1976: 66) - defendido na época por Benjamin Lee Whorf, por exemplo - e sustenta que "toda experiência cognitiva pode ser traduzida e classificada em qualquer língua existente" (JAKOBSON 1976: 67). Tal igualdade de potencial expressivo das mais diversas línguas não significa, porém, que elas sejam iguais. Como aponta Jakobson (1976: 64), inexiste um vínculo estável e universal entre o significado de uma palavra e a "própria coisa" à qual ela se refere. Ou seja, para fazer alguém entender o significado de uma palavra, não basta indicar o objeto ao qual ela remete (JAKOBSON 1976: 64). O exemplo que o linguista usa para ilustrar esse fato é a palavra queijo:

Apontar simplesmente o objeto não nos fará entender se queijo é o nome do espécime dado, ou de qualquer caixa de camembert, ou do camembert em geral, ou de qualquer queijo, de qualquer produto lácteo, alimento ou refresco, ou talvez de qualquer embalagem [...]. (JAKOBSON 1976: 64)

Do mesmo modo, se ambientarmos tal situação para uma sala de aula de ALE, podemos pensar, por analogia, que, se um aprendiz perguntar pelo significado do termo

\footnotetext{
${ }^{9}$ Uma das críticas feitas a esse texto diz respeito à diferenciação essencialista que Jakobson faz entre a linguagem "comum" e a poesia, bem como às consequências que tal distinção básica teriam para a tradução. Tal crítica não invalida, porém, o caráter esclarecedor que o texto pode ter num momento inicial de reflexões sobre a natureza do significado e das palavras e categorias gramaticais, sobretudo num contexto que não vise à formação de tradutores profissionais.
} 
BOHUNOVSKY, R. - Questionando o senso comum sobre mediação/tradução

Schuh, não bastará o docente indicar com o dedo os seus sapatos, pois o aluno não terá certeza sobre se Schuh se refere à categoria "calçado" em geral ou se ao tipo específico de calçado que o professor estará usando no momento (tênis, sandália etc.).

Partindo da premissa da inexistência de uma relação direta entre significado e objeto extralinguístico, Jakobson (1976: 64) distingue "três maneiras de interpretar um signo verbal": a tradução intralingual, que "consiste na interpretação dos signos verbais por meio de outros signos da mesma língua" (JAKOBSON 1976: 64); a tradução interlingual, ou seja, "a interpretação dos signos verbais por meio de alguma outra língua" (JAKOBSON 1976: 65); e a tradução intersemiótica, que corresponde à "interpretação dos signos verbais por meio de sistemas de signos não-verbais"

(JAKOBSON 1976: 65). E são justamente esses os três tipos de tradução às quais costumamos recorrer em sala de aula de LE quando buscamos esclarecer o significado de um termo desconhecido dos aprendizes (por exemplo, a palavra Schuh): ou o explicamos na mesma língua, parafraseando-o (por exemplo: "Das tragen wir an den Füßen"); ou optamos por uma tradução na primeira língua dos aprendizes (no caso dos brasileiros, dizemos "calçado" ou "sapato") ou em outra língua estrangeira que eles entendam; ou, ainda, usamos imagens, gestos ou outros meios não verbais. Por meio dessa classificação, Jakobson procurou mostrar que não é só entre duas línguas que traduzimos: em qualquer uso da linguagem, segundo o pensador russo, "o significado de um signo linguístico não é mais que sua tradução por um outro signo que lhe pode ser substituído" (JAKOBSON 1976: 64) - um olhar ao qual, aliás, podemos recorrer para refletir sobre a mediação numa única língua ou, no caso do alemão, sobre a "mediação

linguística entre o alemão e o alemão" (GLABONIAT et al. 2002: 19). Jakobson (1976) ainda destaca e ilustra com exemplos da língua russa que em qualquer um desses três tipos de tradução (na sinonímia numa só língua ou na tradução interlingual ou intersemiótica) não há equivalência completa. Tal observação pode contribuir para entendermos melhor certas dificuldades em "traduzir" ou encontrar "equivalências" para termos aparentemente banais no par alemão-português em sala de aula. Por exemplo, basta pensarmos em vocábulos aparentemente simples como "Abend" ("tarde"? "noite”? “tardezinha”?), "Wald" ("bosque"? "floresta"? "mato"?) ou "Quark" ("requeijão"? “coalhada"?) para apreendermos a problemática da ideia de equivalentes exatos entre significados de palavras de duas línguas. O texto de Jakobson não apenas ilustra a 
BOHUNOVSKY, R. - Questionando o senso comum sobre mediação/tradução

dificuldade de pensar-se em "equivalência" entre palavras de línguas diferentes, mas também se debruça sobre as consequências das diferenças entre categorias gramaticais desafiando ainda mais o olhar aqui denominado "senso comum" acerca da tradução, geralmente voltado para a questão da correspondência lexical. Segundo Jakobson:

Para traduzir corretamente a sentença inglesa I hired a worker ("Contratei (-ava) um operário / uma operária"), um russo tem necessidade de informações suplementares - a ação foi completada ou não? o operário era um homem ou uma mulher? - porque ele deve escolher entre um verbo de aspecto completivo ou não completivo - nanjal ou nanimal e entre um substantivo masculino ou feminino rabotnika ou rabotnicu. Se eu perguntar ao enunciador da sentença em inglês se o operário é homem ou mulher, ele poderá julgar minha pergunta não-pertinente ou indiscreta, ao passo que, na versão russa dessa mesma frase, a resposta a tal pergunta é obrigatória. (JAKOBSON 1976: 69; grifos do original)

Conforme já mostra a sugestão inserida pelos tradutores brasileiros do texto de Jakobson ("Contratei (-ava) um operário / uma operária"), o português obriga um eventual tradutor a tomar decisões semelhantes àquelas dos tradutores russos. Acrescentemos aqui outro exemplo que pode ilustrar tanto o argumento de Jakobson, quanto a relevância dessa questão para o contexto do ensino de ALE, mesmo num nível inicial: para traduzir a frase "Ich ging in die Schule" para o português, somos obrigados a escolher entre "Eu fui à escola" e "Eu ia à escola" e dar à nossa versão portuguesa da frase um sentido específico. Outra categoria gramatical que pode ter relevância numa atividade tradutória/de mediação é o gênero gramatical. Pensemos, por exemplo, num conto escrito no idioma português em que Sol e Lua ocupam as posições de personagens principais. Muito provavelmente, crianças brasileiras imaginam o Sol como personagem masculino e a Lua como feminina, devido aos gêneros gramaticais correspondentes. Ao vertermos esse conto para o alemão, também precisamos fazer escolhas interpretativas (trocar o gênero das personagens principais para criar uma narrativa mais coerente em alemão? ou explicar - por exemplo, numa nota de rodapé - que se trata de uma tradução do português que atribui ao sol o gênero masculino e à lua, o feminino?) e colocar em xeque a ideia de uma "equivalência" entre termos e textos.

No que diz respeito a questões meramente linguísticas da tradução, Jakobson conclui: “As línguas diferem essencialmente naquilo que devem expressar, e não naquilo que podem expressar" (JAKOBSON 1976: 69; grifos do original). Apesar das críticas recebidas, "Aspectos linguísticos da tradução" é um texto clássico dos Estudos da Tradução. Em nosso contexto de ensino de LE, podemos utilizá-lo como um ponto de partida para reflexões acerca de aspectos terminológicos e gramaticais da tradução e/ou 
BOHUNOVSKY, R. - Questionando o senso comum sobre mediação/tradução

da mediação. Jakobson assinala a obrigatoriedade de tomarmos decisões interpretativas ao vertermos um texto de uma língua para outra. Trata-se de mera ilusão que a tradução possa ser uma simples "transmissão" ou "reprodução" daquilo que entendemos ser o sentido do texto fonte.

A partir desse primeiro questionamento de uma visão de tradução enraizada no senso comum, sugerimos, como próximo passo, a leitura de um texto que aponta caminhos para fazer as escolhas (das quais não se pode fugir durante o ato tradutório) com competência, consciência e capacidade para justificá-las.

\section{$3 \bigcirc$ objetivo da tradução: "Possíveis relações entre texto fonte}

\section{e texto alvo" (Christiane Nord)}

Nas últimas décadas, os Estudos da Tradução têm se desenvolvido e firmado como uma área acadêmica inter- e transdisciplinar de destaque, com inúmeras vertentes teóricas e interesses temáticos e políticos diversos. Dessas muitas vertentes, uma tem sido mencionada por alguns autores - tais como Elisabeth Kolb (2016) e Daniel Reimann (2016), por exemplo, assim como em sites do Instituto Goethe ${ }^{10}$ sobre o tema da mediação linguística - como de interesse especial para a reflexão sobre mediação no âmbito do ensino de LE. Trata-se da escola da tradução funcional, associada com a Teoria do Escopo. No contexto brasileiro, as dissertações de mestrado de Jenny Fischer (2012) e Virgínia Wruck (2016), ambas defendidas na Universidade Federal do Paraná (UFPR), também sugerem possíveis ganhos para o ensino de LE advindos das bases teóricas dessa corrente. Dentre os estudos que advogam em favor de um diálogo mais intenso entre as áreas de ensino de LE e Estudos da Tradução, a linha associada à tradução funcional tem sido a mais citada.

Kolb constata que hoje "a tradução não é mais tão vista como transferência linguística, quanto o é como transferência contextualizada para o destinatário da cultura alvo" (KolB 2016: 104). A estudiosa cita uma definição de Katharina Reiß e Hans J. Vermeer - dois dos fundadores da referida vertente - que seria a base da Teoria do Escopo: "O que domina toda tradução é o seu objetivo" (REIß; VERMEER apud KolB

\footnotetext{
${ }^{10}$ Cf. http://www.goethe.de/ins/si/de/spr/mag/21261529.html.
} 
BOHUNOVSKY, R. - Questionando o senso comum sobre mediação/tradução

2016: 104). Em outras palavras, está em primeiro plano o objetivo, a meta, a função que uma tradução deve cumprir, ou seja, o seu escopo, e não mais a maneira como é realizada ou sua semelhança linguística com o texto fonte. Kolb ainda ressalta outro aspecto relevante para a área de ensino-aprendizagem de LE: "Como toda tradução tem seu objetivo bem específico e como cada texto pode ser traduzido com objetivos diferentes, é preciso definir o escopo novamente a cada vez e com exatidão" (KOLB 2016: 104). Nas propostas didáticas para o ensino de uma LE segundo o QECR que encontramos em Profile Deutsch..., os descritores linguísticos (“Kannbeschreibungen”) (GLABONIAT et al. 2002) já seguem nessa direção, pois não exigem nem preveem a tradução de palavras ou de frases descontextualizadas. Simulam situações cotidianas que dão indícios do objetivo comunicativo, a função - ou seja, o escopo - que a atividade realizada deverá cumprir. Por exemplo, para o nível A2: o aprendiz deve ser "capaz de resumir para uma vendedora que fala alemão o que seu amigo deseja comprar" (GLABONIAT et al. 2002: 97). Ou para o nível B2: o aprendiz deve ser capaz "de informar uma colega alemã em língua alemã sobre os detalhes importantes de um contrato de aluguel em outra língua" (GLABONIAT et al. 2002: 139). Mais do que exatidão linguística, o que irá definir se essa tarefa foi cumprida com sucesso ou não pelo mediador é a "solução" para a situação, o sucesso desse amigo em obter as informações almejadas sobre os produtos da loja.

Atualmente, o nome de maior destaque no contexto da Teoria do Escopo é o de Christiane Nord. A obra dessa teórica alemã já foi vertida para diversas línguas, mas no Brasil temos apenas um livro traduzido e publicado. Junto com um grupo de alunos do curso de Tradução da Universidade Federal de Santa Catarina (UFSC), Meta Elisabeth Zipser verteu para o português brasileiro a obra Textanalyse und Übersetzen: Theoretische Grundlagen, Methode und didaktische Anwendung einer übersetzungsrelevanten Textanalyse, cuja primeira edição saiu em 1988. A versão brasileira veio a lume em 2016, sob o título Análise textual em tradução: bases teóricas, métodos e aplicação didática. Exigir a leitura integral dessa obra de referência da escola funcionalista de tradução no contexto de formação de futuros professores de LE, embora desejável, talvez não seja exequível. Por isso, nosso foco recai aqui sobre um subcapítulo dessa publicação, de apenas 13 páginas, que, no nosso entender, pode contribuir substancialmente para colocar em questão o senso comum acerca da atividade tradutória, seja ela profissional ou não. O subcapítulo chama-se "Possíveis relações entre texto fonte 
BOHUNOVSKY, R. - Questionando o senso comum sobre mediação/tradução

e texto alvo" (NORD 2016: 51-63) e inicia-se, justamente, com uma observação a propósito do senso comum a respeito do que seja tradução:

Normalmente se espera que uma tradução reproduza "fielmente" todos os elementos relevantes do texto original. Trata-se de uma expectativa bastante comum, muitas vezes também sustentada por linguistas e teóricos literários, mesmo que o conceito de "fidelidade" possa ser equiparado a "equivalência" [...].

Ou seja, Nord resume aqui o que, no presente artigo, temos denominado "senso comum" acerca da tradução. Logo depois, a autora inicia sua argumentação crítica sobre tal visão:

Esta equação pouco aprofundada de tradução e equivalência parece ser responsável pelos eternos debates acerca da fidelidade ou da liberdade na tradução, debates esses que não nos têm levado a lugar nenhum. (NORD 2016: 51)

Conforme Nord aponta logo a seguir, diversos estudiosos da tradução têm se esforçado para chegar a uma definição válida e abrangente do conceito de equivalência, percorrendo assim um "longo e tortuoso caminho via a [sic] especificação da equivalência denotativa, conotativa, normativa, pragmática e formal [...]” (NORD 2016: 52). O resultado dessa procura pela equivalência - considerada por Nord um "conceito ambíguo" (NORD 2016: 52) - tem sido uma constante insatisfação dos tradutores e dos críticos com traduções produzidas e publicadas, pois nenhum texto está livre de discrepâncias e diferenças em relação ao texto fonte, inclusive nos "níveis mais elementares (por exemplo, no nível das palavras e frases)" (NORD 2016: 52).

Tais considerações de Nord remetem a dois aspectos relevantes não apenas para tradutores profissionais, mas também para a mediação linguística cotidiana, que nos interessa aqui: primeiro, o conceito de equivalência talvez não seja o único e nem o mais útil para chegarmos a produtos tradutórios adequados; segundo, a tradução não deve ser entendida em "níveis elementares", como palavras e frases (algo bastante comum em nosso contexto de ensino de LE), mas em nível de texto. Para Nord, a "tradução é a produção de um texto alvo funcional, mantendo-se uma relação com um determinado texto fonte que é especificado de acordo com a função pretendida ou exigida do texto alvo (skopos)" (NORD 2016: 61; ênfase nossa). Ou seja, mesmo numa situação cotidiana de mediação linguística, traduzimos textos que, como sabemos, sempre estão ambientados em certo contexto. E é esse contexto que define o porquê da tradução ou mediação e, consequentemente, a função que o texto alvo deve cumprir (denominada “escopo"). A prioridade do escopo de uma tradução, em negligência da "coerência 
BOHUNOVSKY, R. - Questionando o senso comum sobre mediação/tradução

intertextual com o texto fonte" (NORD 2016: 57), e o compromisso do tradutor/mediador com a situação alvo não apenas coloca em questão a ideia de poder haver uma definição única e/ou clara para o conceito de equivalência, mas também abre um caminho interessante para pensarmos a mediação linguística em sala de aula, para elaborarmos atividades didáticas e, inclusive, para avaliarmos essas atividades no contexto de ensino de LE.

No referido subcapítulo, Nord (2016) apresenta uma série de exemplos que ilustram como se dá na prática a pertinência de suas reflexões teóricas e que ajudam a entender sua proposta de tradução funcional. Num deles, que diz respeito à tradução do espanhol para o alemão do livro Otra historia de España, de Fernando Díaz Plaja, Nord

se concentra na pergunta sobre qual seria a melhor maneira de traduzir "Partido de Azaña" numa frase do texto fonte que trata da ausência de comunistas no governo espanhol de 1936. Conforme Nord (2016: 57), o “equivalente alemão 'normal' seria 'Azaña Partei', mas este não é o nome oficial do partido (que oficialmente se chama 'Partido de Izquierda Republicana')". Além disso, "seria apenas de interesse dos receptores do TA [texto alvo]" (NORD 2016: 57) a possibilidade de associar algo com o nome Azaña, fundador do partido, coisa que não pode ser presumida pelo público-alvo alemão. Sem propor uma tradução "correta" para esse caso, Nord destaca que o eventual tradutor teria que "decidir se quer expandir o texto, fornecendo mais informações sobre Azaña, ou substituir a alusão pelo nome oficial do partido" (NORD 2016: 57).

Com esse e diversos outros exemplos, Nord mostra que a atividade de tradução/mediação não é um trabalho neutro que consiste em procurar supostas equivalências entre palavras, significados ou textos, mas sim um processo de que envolve tomar decisões sobre como produzir um texto alvo que cumpra sua função pretendida num novo contexto.

Partindo dessa perspectiva, podemos pensar em atividades de ensino de LE inspiradas no QCER e nos descritores linguísticos. Exemplo 1: ao verter um anúncio de aluguel para uma colega alemã que se encontra no Brasil, mas não fala português, o mediador brasileiro que traduz "apartamento de dois quartos" para "2-Zimmer Wohnung" elabora um texto alvo que poderíamos entender como linguisticamente "equivalente" ao texto-fonte. Porém, o texto alvo produzido não é adequado, pois em língua alemã a sala de estar é considerada um "quarto". Exemplo 2: a pedido de um 
BOHUNOVSKY, R. - Questionando o senso comum sobre mediação/tradução

estudante brasileiro que pretende estabelecer um primeiro contato com um potencial orientador de doutorado em Berlim, uma alemã aceita traduzir para a sua língua um $e$ mail que o estudante escreveu em português com essa finalidade. Ao traduzir "Caro professor Thomas Kurz" como "Lieber Professor Thomas Kurz", gera-se, mais uma vez, um resultado que certamente se justifica a partir de consultas a um dicionário, mas que não seria um produto tradutório apropriado em relação à função almejada. Obviamente, em outro texto e em outro contexto, "caro" poderia, sim, ser traduzido como "Lieber". Exemplo 3: ao mediar uma conversa entre uma pessoa prolixa, cuja tendência é repetir várias vezes as mesmas informações, e outra interessada em receber apenas as informações de que precisa para resolver uma situação em que se encontra, o mediador pode chegar a um resultado satisfatório de sua atividade ao verter o texto fonte (oral ou escrito) para um texto alvo muito mais sucinto que o texto fonte. O que define a adequação funcional de um termo, de um período ou de um texto traduzido não é, portanto, alguma "equivalência" em nível terminológico em relação ao texto fonte, mas sim o fato de o texto alvo como um todo estar adequado ao seu novo contexto. O referido subcapítulo de Nord inclui também um comentário interessante sobre aquilo que nos termos de Jakobson (1976) é chamado de "tradução intralingual” ou em Glaboniat et al. (2002: 19), de "mediação entre alemão e alemão", pois, ainda no que se refere ao texto em que consta o nome "Partido de Azaña", Nord coloca em questão "uma das objeções frequentes" (NORD 2016: 57) à tradução: a suposição de que ela "apenas permite adaptações que não seriam necessárias na comunicação intralingual” (NORD 2016: 57). De acordo com a teórica, tal “argumento não é válido, uma vez que os mesmos problemas de compreensão podem surgir para um jovem espanhol (ou argentino ou peruano) de hoje" (NORD 2016: 57) que não possua conhecimento histórico e cultural sobre a pessoa de Azaña e a Espanha dos anos 1930. Com isso, cai por terra outra crença vinculada ao senso comum sobre línguas e tradução, qual seja: a de que a comunicação entre duas línguas seria fundamentalmente diversa da comunicação em uma só língua. Surge uma visão de tradução que amplia suas características para qualquer ato de comunicação. O grande filósofo e linguista George Steiner constata: “Os meios de problemas estruturais e operacionais essenciais do ato de traduzir estão integralmente presentes nos atos de fala, de escrita ou de codificação pictórica no interior de qualquer língua" (STEINER 2005: s/p.). A partir dessa constatação, Steiner desenvolveu ricas reflexões sobre suas implicações nos estudos literários. Como esses pensamentos muitas vezes vão muito

Pandaemonium, São Paulo, v. 25, n. 46, mai.-ago. 2022, p. 12-33 
BOHUNOVSKY, R. - Questionando o senso comum sobre mediação/tradução

além do que entendemos como relevante para o ensino de uma LE, consideramos que a Teoria do Escopo pode contribuir para pensar sobre a mediação (inclusive dentro de um mesmo idioma) em sala de aula, com base numa compreensão de língua e comunicação adequada para seu usuário profissional.

As premissas teóricas e as propostas práticas de Nord podem trazer diversas contribuições para um debate sobre a mediação no âmbito do ensino de LE, como também para a criação de atividades e materiais didáticos e para a avaliação de atividades de mediação. Em nível teórico, Nord questiona a concepção de que a coerência intertextual entre texto fonte e texto alvo (oral ou escrito) seja central para um resultado de sucesso, ou bem avaliado, de mediação. Se é o escopo que "tem prioridade frente à coerência intertextual com o texto fonte" (NORD 2016: 57), podemos imaginar um texto que resulte de uma mediação linguística e que tenha pouca semelhança com o texto fonte, mas que tenha resolvido com sucesso a situação comunicativa em que foi produzido, conforme mencionado acima. Para a produção de material ou atividades didáticas, a Teoria do Escopo reforça a necessidade de definir-se muito bem o contexto (mesmo que fictício) e o objetivo da ação mediadora que os aprendizes devem empreender. Um enunciado como "traduza o seguinte texto para o português" torna-se, assim, absolutamente improdutivo, já que sem a definição exata do objetivo e do destinatário não é possível produzir um resultado funcionalmente adequado.

Nord ainda ressalta um ponto importante, não mencionado por Jakobson e esquecido com frequência em trabalhos mais recentes na nossa área: qualquer tradução e/ou mediação não é uma operação realizada entre palavras ou sentenças, mas sempre entre textos (embora estes possam ser compostos por apenas uma palavra ou uma sentença). Como corolário dessa premissa, a teórica alemã defende que o que determina o grau de sucesso de uma tradução ou mediação é se o texto traduzido cumpre sua função no seu novo contexto (em geral, diferente do contexto do texto fonte). Em linguagem acessível e oferecendo como exemplos textos utilitários, a autora ajuda a desviar o olhar de questões meramente linguísticas e a entender a importância fulcral de "considerar as exigências especiais da situação alvo prospectiva" (NORD 2016: 53). Assim, coloca em questão conceitos tradicionais como "fidelidade" e "equivalência" e os substitui pela ideia da "lealdade", que contempla tanto o autor, como também o receptor do texto. No 
BOHUNOVSKY, R. - Questionando o senso comum sobre mediação/tradução

nosso entender, suas obras são mais um passo inicial, porém fundamental, para pôr em xeque uma concepção de tradução fundada no senso comum.

\section{Um clássico dos Estudos da Tradução brasileiros: Oficina de}

\section{Tradução (Rosemary Arrojo)}

Rosemary Arrojo é uma teórica de tradução brasileira cuja pesquisa alcança grande repercussão nacional e internacional. Algumas de suas propostas teóricas foram alvos de críticas e polêmicas - por exemplo, por parte do tradutor e teórico Paulo Henriques Britto. Porém, apesar de rejeitar algumas das premissas de Arrojo, o próprio Britto destaca que ela "escreveu, além de artigos teóricos influentes, um livro que considero uma das melhores obras introdutórias de nosso tema, leitura recomendável para todo iniciante: Oficina de tradução" (BRITTO 2012: 45). É esse livro que propomos incluir na lista de leituras sugeridas sobre tradução durante o processo formativo de professores de LE. O livro foi lançado em 1986 e reeditado diversas vezes na série Princípios, pela Editora Ática. É de linguagem acessível e envolvente, e conta com apenas 85 páginas.

Em Oficina de tradução: a teoria na prática, Arrojo (2000) versa sobre conceitos teóricos básicos da tradução, levantando questões tais como: o tradutor pode ser neutro e/ou invisível?; o que faz de um texto um texto literário?; o que é a fidelidade? Embora tenha como foco a tradução literária, traz reflexões e exemplos intrigantes e pertinentes para a tradução/mediação de outros gêneros textuais. Vejamos um exemplo que ela fornece no primeiro capítulo (de apenas quatro páginas), que trata do título do livro. A primeira frase é: "Provavelmente o leitor nunca tenha ouvido falar numa oficina de tradução" (ARROJO 2000: 7). Vale lembrar que a obra foi escrita em 1986 e que a justificativa que Arrojo apresenta a seguir para essa primeira frase não corresponde mais à situação atual - mas é justamente esse fato que pode tornar a discussão interessante e ilustrativa para o debate que ela propõe. Segundo Arrojo, no Brasil de 1986, "oficina de tradução" não existia como "expressão já construída e consagrada pelo uso" (ARROJO 2000: 7). Em inglês, havia a expressão "Translation Workshop" (ARROJO 2000: 9), nome de um curso "mais prático que teórico" que a autoria havia feito nos EUA (ARROJO 2000: 9) e associado com um tipo de "curso regular sobre algum assunto especializado" 
BOHUNOVSKY, R. - Questionando o senso comum sobre mediação/tradução

(ARROJO 2000: 9). Ao procurar por uma versão adequada para o nome em português, essa paráfrase seria uma primeira opção tradutória, considerada, porém, "não muito satisfatória" (ARROJO 2000: 9) pela autora - provavelmente pelo fato de que a ideia de um curso regular sobre tradução não cumpriria as expectativas e convenções em relação ao título de um livro em contexto brasileiro. Assim, Arrojo decidiu empregar em nosso meio o nome "Oficina de tradução", ainda com um "sentido figurado e inesperado" (ARRojo 2000: 10). Talvez em outro contexto, em que um estudante tenha que explicar e “traduzir" a expressão translation workshop para um colega, a paráfrase pudesse ter sido mais adequada. Se por um lado esse exemplo mostra que mesmo a tradução de uma expressão aparentemente simples como essa traz consigo a necessidade de o tradutor tomar decisões e produzir novos significados, de acordo com as necessidades do novo contexto, por outro lado ele pode ser usado também para ilustrar que as línguas estão em constante transformação. Pois, como todo estudante brasileiro de tradução bem sabe, a partir de 1986 a expressão "oficina de tradução" se estabeleceu em nosso país como termo "construído e consagrado pelo uso" - para repetir a definição mencionada por Arrojo - e utilizado com frequência em cursos de tradução com as características mencionadas por Arrojo, conforme expusemos logo acima. Aliás, foi o livro de Arrojo que contribuiu para que "oficina de tradução" deixasse de ter um sentido metafórico, tornando-se um termo comum para designar inúmeros encontros de tradutores (em formação) Brasil afora, cujos participantes têm interesse em discutir suas próprias traduções ou traduções já consagradas.

No segundo capítulo dessa obra, Arrojo propõe uma reflexão sobre o desejo de muitos tradutores de serem "invisíveis", ou seja, de não interferirem na produção de significados de um ato comunicativo, mas almejando "apenas" transportar o sentido de um texto para outra língua, dizer a mesma coisa em outra língua. Usando um conto de Jorge Luiz Borges como base, Arrojo desconstrói a ideia de que um tradutor/mediador poderia ser um "transportador" de significados, e chega à conclusão de que, a partir de uma perspectiva teórica mais atual, não apenas a tradução, mas também a leitura “deixa de ser [...] uma atividade que protege os significados 'originais' de um autor, e assume sua condição de produtora de significados" (ARROJO 2000: 24; grifo da autora).

Embora, como já foi dito, a argumentação de Arrojo em Oficina de tradução... se refira à tradução literária, há vários motivos que justificam que o livro seja considerado 
BOHUNOVSKY, R. - Questionando o senso comum sobre mediação/tradução

uma leitura recomendável e útil durante o processo de formação de docentes de LE. Em primeiro lugar, porque a tradução literária tem sido discutida por diversos autores da nossa área (por exemplo: Kramsch, HuffMeister 2008; PASEWALcK, NeIDLinger, LoOGUS 2014) como uma ferramenta válida para os aprendizes alcançarem maior consciência linguística e/ou cultural. Em segundo lugar, porque o questionamento de Arrojo sobre a tentativa de separação entre aquilo que seria "literário" e o que seria "não literário", seus apontamentos e exemplos com respeito à impossibilidade de defender limites claros entre os diferentes gêneros textuais e classes de textos, assim como entre a tradução "literária" e a "não literária", trazem insights significativos para nosso objetivo de sacudir as bases do senso comum enraizadas em muitos (futuros) professores de LE. As palavras finais do livro, que resumem o argumento central defendido ao longo da obra, não deixam dúvida de que os apontamentos presentes nessa obra de Arrojo podem contribuir para uma formação acadêmica consistente dos futuros docentes de ALE. São elas:

Cada tradução (por menor e mais simples que seja) exige do tradutor a capacidade de confrontar áreas específicas de duas línguas e duas culturas diferentes, e esse confronto é sempre único, já que suas variáveis são imprevisíveis (ARROJO 2000: 78).

Arrojo ainda oferece uma lista de verbetes intitulada "Vocabulário crítico". Dois dos verbetes nos parecem de maior pertinência para o contexto de LE. O primeiro é "comunidade interpretativa": "cunhado pelo teórico [...] Stanley Fish, o conceito [...] se refere ao conjunto de elementos responsáveis, numa determinada época e numa determinada sociedade, pela emergência de significados aceitáveis" (ARROJO 2000: 79). Já que, segundo a autora, o "significado não se encontra [...] para sempre depositado na palavra ou no texto" (ARROJO 2000: 79), é preciso entender que ele se forma "a partir da ideologia, dos padrões estéticos, éticos e morais, das circunstâncias históricas e da psicologia que constituem a comunidade sociocultural em que se interpreta esse texto ou essa palavra" (ARROJO 2000: 79).

Tal olhar acerca da produção e da instabilidade de significados remete-nos, se voltarmo-nos ao âmbito de ALE, às reflexões teóricas desenvolvidas por Claus Altmayer (2013, por exemplo) a propósito do processo de "aprendizagem cultural" e "discursiva", em estreito diálogo com os Estudos Culturais. Entendemos que a introdução aos conceitos centrais de tradução que Arrojo fornece nesse seu pequeno livro que já se tornou um clássico pode ser também uma ótima entrada para o universo de debates sobre a mediação 
BOHUNOVSKY, R. - Questionando o senso comum sobre mediação/tradução

linguística de um modo mais geral e às teorias discursivas dos Estudos Culturais no contexto de ensino de LE.

O segundo verbete que destacamos aqui é também o último do "Vocabulário crítico" de Arrojo, qual seja: "tradução". Como vimos no começo deste artigo, em diversas publicações referentes à mediação linguística no ensino de LE, essa atividade é definida como uma "transmissão" ou uma "reprodução" de significados, os quais deveriam ficar supostamente inalterados nesse processo de mediação. A definição de Arrojo para o termo resume a argumentação de seu livro e ressalta, mais uma vez, a importância de se repensar o senso comum acerca daquilo que entendemos por tradução:

de acordo com a etimologia, tradução (do latim traductione) significa "ato de conduzir além, de transferir", acepção desenvolvida também pelas teorias de tradução criticadas neste livro. O que Oficina de tradução propõe é o reconhecimento do caráter essencialmente criativo do processo de tradução. Como tentamos demonstrar, traduzir, mas do que transferir, é transformar: "transformar uma língua em outra, e um texto em outro" (Jacques Derrida). (ARROJO 2000: 80)

\section{Considerações finais}

Como vimos na primeira seção deste artigo, Elisabeth Kolb, em Sprachmittlung... (KoLB 2016), empenha-se para demostrar que a mediação linguística não é uma ferramenta para alcançar outros objetivos de ensino, mas uma competência complexa por si só, cujo ensino em sala de aula promove diversas "competências parciais" ("Teilkompetenzen") (KolB 2016: 161): a linguística, a discursiva, a pragmática, a interacional, a sociolinguística, a estratégica, a factual, a (inter)cultural, a instrumental, a pessoal e a de transferência. Não surpreende que Kolb também destaque a importância de promover o diálogo entre as áreas de ensino de LE e de Estudos da Tradução - sobretudo sua vertente funcional (KOLB 2016). ${ }^{11}$

Os demais textos aqui apresentados, por sua vez, podem contribuir para pôr em xeque o senso comum que ainda vigora a respeito do que seja tradução e para melhor

\footnotetext{
${ }^{11}$ Na parte final de seu livro, Kolb (2016) ainda apresenta algumas reflexões e propostas para a prática de ensino de LE, para a progressão da competência de mediação linguística e sobre a importância de oferecer aos aprendizes enunciados claros e que informem sobre o contexto e o objetivo do tipo de mediação que devem desenvolver, bem como outros aspectos relevantes para a sala de aula (KolB 2016). No presente artigo, essas questões não puderam ser tematizadas.
} 
BOHUNOVSKY, R. - Questionando o senso comum sobre mediação/tradução

compreender a complexidade de qualquer situação em que alguém precisa assumir o papel do mediador.

Acreditamos que as reflexões e discussões sobre alguns dos aspectos centrais da tradução/mediação em consonância com as bases teóricas mais atuais dos Estudos da Tradução sejam um ponto de partida adequado para a posterior produção, avaliação ou aplicação de atividades didáticas que envolvam a mediação no contexto de sala de aula de LE.

Para finalizar o presente artigo - e, quem sabe, dar início a reflexões sobre as implicações de seus argumentos para a prática -, resumimos alguns dos pontos aqui abordados que consideramos os mais relevantes. Com base nas ponderações dos autores cujos textos apresentamos, fica claro que qualquer proposta didática que tenha como objetivo o desenvolvimento da competência de mediação linguística dos aprendizes deve considerar: que a ideia da "equivalência" na tradução/mediação deve ser substituída pelo conceito de "adequação" do texto alvo ao seu novo contexto; o fato de que tradução nunca é reprodução, mas sempre produção de significados e textos; a importância de definir clara e coerentemente o objetivo da tarefa de mediação proposta aos aprendizes (tanto para que eles possam efetuá-la, como também para podermos avaliar o texto alvo); a pertinência das diferenças entre as características dos gêneros textuais em línguas distintas; a impossibilidade de pensarmos a tradução/mediação em nível de palavras sem levarmos em conta o contexto e o objetivo da atividade.

\section{Referências bibliográficas}

AltMAYER, Claus. Die DACH-Landeskunde im Spiegel aktueller kulturwissenschaftlicher Ansätze. DEMMIG, Silvia; HÄGI, Sara; SCHWEIGER, Hannes (Org.). DACHLandeskunde: Theorie - Geschichte - Praxis. München: Iudicium, 2013, 15-31.

ArRoJo, Rosemary. Oficina de tradução: a teoria na prática. 4.ed. São Paulo: Ática, 2000.

BOHUNOVSKY, Ruth. "A tradução no ensino de línguas: vocabulário, gramática, pragmática ou consciência cultural?" Trabalhos de Linguística Aplicada, v. 50, n. 1, 205-217, 2011. Disponível em: http://doi.org/10.1590/S0103-18132011000100012 (14/03/2021).

BRITTO, Paulo Henriques. A tradução literária. Rio de Janeiro: Civilização Brasileira, 2012.

CONSELHO DA EUROPA. Quadro europeu comum de referência para as línguas: aprendizagem, ensino, avaliação. Tradução de Maria Joana Pimentel do Rosário e Nuno Verdial Soares. Porto: Edições ASA, 2001. (Colecção Perspectivas Actuais/Educação).

ECO, Umberto. Quase a mesma coisa: experiências de tradução. Tradução de Eliana Aguiar. Rio de Janeiro: BestBolso, 2011. 
BOHUNOVSKY, R. - Questionando o senso comum sobre mediação/tradução

EvANGELISTA, Maria C. "Atividades tradutórias para ensino de alemão: uma análise baseada em argumentos contrários à tradução no ensino línguas estrangeiras". Pandaemonium Germanicum, v. 22, n. 38, 1-30, 2019. Disponível em: http://doi.org/10.11606/1982$883722381(14 / 03 / 2021)$.

FISCHER, Jenny. Übersetzen als Sprachmittlung im Deutsch-als-Fremdsprache-Unterricht. Sprachmittlung als fünfte Fertigkeit und/oder Übungsform? Über das didaktische Potential von Sprachmittlungsaufgaben mit Beispielen für den brasilianischen DaFUnterricht. Dissertação (Mestrado bilateral em Letras) - Programa de Pós-Graduação em Letras, Universidade Federal do Paraná, Curitiba; Universität Leipzig, Leipzig, 2012. Disponível em: http://acervodigital.ufpr.br/handle/1884/36198 (14/03/2021).

Glaboniat, Manuela et al. Profile Deutsch: Gemeinsamer Europäischer Referenzrahmen. Berlin: Langenscheidt, 2002.

Gnutzmann, Claus; Küster, Lutz; Schramm, Karen (Org.). Fremdsprachen Lehren und Lernen (FLuL), Tübingen, 48. Jahrgang, Heft 2, 2019. (Themenschwerpunkt: Sprachmittlung).

JAKOBSON, Roman. Aspectos linguísticos da tradução. In: JAKOBSON, Roman. Linguística e comunicação. Tradução de Izidoro Blikstein e José Paulo Paes. São Paulo: Cultrix, 1976, 63-72.

KolB, Elisabeth. Sprachmittlung: Studien zur Modellierung einer komplexen Kompetenz. (Münchener Arbeiten zur Fremdsprachen-Forschung). Münster: Waxmann, 2016.

KramsCH, Claire; HuffMEISTER, Michael. The Political Promise of Translation. In: Fremdsprachen Lehren und Lernen (FLuL), Band 37, Nr. 1, S. 283-297, 2008. Disponível em: http://elibrary.narr.digital/article/99.125005/flul200810283 (14/03/2021).

NORD, Christiane. Possíveis relações entre texto-fonte e texto alvo. In: NORD, Christiane. Análise textual em tradução: Bases teóricas, métodos e aplicação didática. Tradução e adaptação coordenadas por Meta Elisabeth Zipser. São Paulo: Rafael Copetti Editor, 2016. (Coleção Transtextos; v. 1). Disponível em: http://repositorio.ufsc.br/bitstream/handle/123456789/186875/An\%C3\%A1lise\%20Text ual\%20 em\%20Tradu\%C3\%A7\%C3\%A3o.pdf?sequence=1\&isAllowed=y $(14 / 03 / 2021)$.

PasewalcK, Silke; NeIDlinger, Dieter; LoOgus, Terje (Org.). Interkulturalität und (literarisches) Übersetzen. Tübingen: Stauffenberg Verlag, 2014.

ReIMAnN, Daniel. Sprachmittlung. Tübingen: Narr Francke Attempto, 2016.

Reiss, Katharine; Vermeer, Hans J. Grundlagen einer allgemeinen Translationstheorie. Tübingen: Max Niemeyer, 1984.

RoDRIGUES, Cristina Carneiro. Tradução e diferença: uma proposta de desconstrução da noção de equivalência em Catford, Nida, Lefevere e Toury. 1998. 241f. Tese (Doutorado) Universidade Estadual de Campinas, Instituto de Estudos da Linguagem, Campinas, SP. Disponível em: http://www.repositorio.unicamp.br/handle/REPOSIP/271182.

Rodrigues, Cristina Carneiro. Tradução: A questão da equivalência. Alfa. São Paulo, v. 44, 2000, 89-98.

RÖSSLER, Andrea; SCHÄDLICH, Birgit. Sprachmittlung revisited: Neue Perspektiven und Herausforderungen in Zeiten des Companion Volume zum GER. In: GNUTZMANN, Claus; KÜSTER, Lutz; SCHRAMM, Karen (Org.). Fremdsprachen Lehren und Lernen (FLuL), Tübingen, 48. Jahrgang, Heft 2, 10-28, 2019. (Themenschwerpunkt: Sprachmittlung).

STEINER, George. Depois de Babel: Questões de linguagem e tradução. Tradução de Carlos Alberto Faraco. Curitiba: Editora da UFPR, 2005.

ÜBERSETZEN IM DEUTSCHUNTERRICHT. Fremdsprache Deutsch, Stuttgart, Heft 23, 2000.

Pandaemonium, São Paulo, v. 25, n. 46, mai.-ago. 2022, p. 12-33 
BOHUNOVSKY, R. - Questionando o senso comum sobre mediação/tradução

WEININGER, Markus J. Algumas reflexões inevitáveis sobre a tradução de poesia. In: BLUME, Rosvitha Friesen; WEININGER, Markus J. (Org.). Seis décadas de poesia alemã: Do pósguerra ao início do século XX. Florianópolis: Ed. da UFSC, 2012, 193-216.

WRUCK, Virgínia. Übersetzen und kulturelles Lernen im Fremdsprachenunterricht: Eine Fallstudie zur Erforschung kulturbezogener Lernprozesse. 132 f. Dissertação (Mestrado bilateral em Letras) - Programa de Pós-Graduação em Letras, Universidade Federal do Paraná, Curitiba; Universität Leipzig, Leipzig, 2016. Disponível em: http://acervodigital.ufpr.br/handle/1884/48549 (14/03/2021).

Recebido em 26 de março de 2021

Aceito em 31 de maio de 2021 